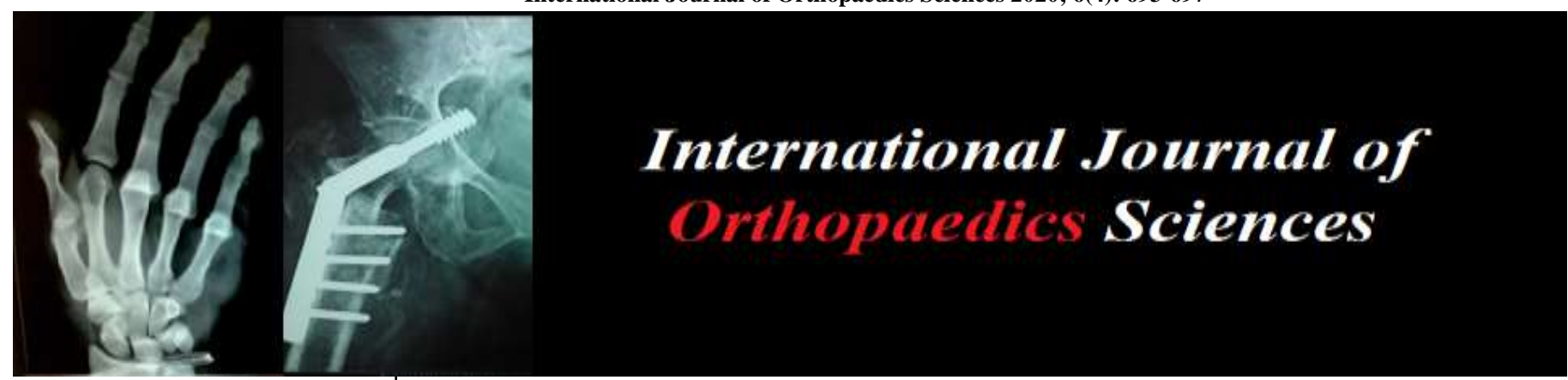

E-ISSN: 2395-1958

P-ISSN: 2706-6630

IJOS 2020; 6(4): 693-697

(C) 2020 IJOS

www.orthopaper.com

Received: 09-08-2020

Accepted: 17-09-2020

Dr. Kandasamy Ganeshsankar Kandasamy

Associate Professor, Department of Orthopaedics, Vinayaka

Missions Kirupananda Variyar

Medical College and Hospital,

Salem, Tamil Nadu, India

Dr. Meenakshi Sundaram

Kandasamy

Associate Professor, Department

of Orthopaedics, Vinayaka

Missions Kirupananda Variyar

Medical College and Hospital,

Salem, Tamil Nadu, India

Dr. R Shankar

Professor, Department of

Preventive and Social Medicine,

Vinayaka Missions Kirupananda

Variyar Medical College and

Hospital, Salem, Tamil Nadu,

India
Corresponding Author:

Dr. Kandasamy Ganeshsankar Kandasamy

Associate Professor, Department of Orthopaedics, Vinayaka

Missions Kirupananda Variyar

Medical College and Hospital,

Salem, Tamil Nadu, India

\section{A study on functional outcome of osteosynthesis for fracture proximal tibia}

\author{
Dr. Kandasamy Ganeshsankar Kandasamy, Dr. Meenakshi Sundaram \\ Kandasamy and Dr. R Shankar
}

DOI: https://doi.org/10.22271/ortho.2020.v6.i4j.2408

\section{Abstract}

Background: The ultimate objective in the management of tibial plateau fracture is to ensure anatomic reduction, restore the axial alignment and maintain a stable fixation such a way to prevent the secondary displacement of fracture fragment. The various type of managing the tibial plateau fractures apart from conservative management are open reduction and internal fixation, closed reduction and percutaneous fixation and hybrid type of external fixation.

Aim: To evaluate the functional outcome of osteosynthesis of tibial plateau fractures using different surgical techniques after a minimum period of 6 months by using Rasmussen scoring system.

Methodology: All patients with proximal tibial fracture in the age group between 20 and 60 years were included as our study subjects. A total of 38 patients were taken as our study subjects. The tibial fractures were classified based on schatzker type of fracture classification. Fracture reduction was done under Carm guidance by closed methods using ligamentotaxis. After confirming the reduction under $\mathrm{C}$-arm guidance fixation of the fracture was done with locking plate. Functional outcome assessment of knee joint was done after six months post-operatively by using Rasmuseen score, which includes pain perception, walking capacity, extension at knee joint, range of movements and stability.

Results: Majority of the patients who had undergone closed reduction with cancellous screw procedure or open reduction and internal fixation with buttress plate and bone graft had the functional outcome between excellent and good whereas patients who had underwent dual plating had a fair to poor outcome and this difference was found to be statistically significant. Pain and knee stiffness were reported in very few patients at the end of 6 months.

Conclusion: In the management of tibial plateau fractures, open reduction with internal fixation using plate screws with lesser soft tissue dissection would lead to excellent functional outcome.

Keywords: Tibial plateau fracture, open reduction and internal fixation, Rasmuseen score, functional outcome

\section{Introduction}

Knee joint is one of the major weight bearing joint in the human body. It is the most commonly injured joint either due to accidental fall or related to sports injury. Fractures occurring in the proximal tibia and extending into the articular surface of the knee joint is called as tibial plateau fractures ${ }^{[1]}$. The most common mode of tibial plateau fracture is either from direct axial compression or due to indirect shearing force. The following are the factors that determine the nature of tibial fracture they are the direction and magnitude of the force, position of the leg at the time of injury and the quality of bone (bone density). The overall prevalence of tibial plateau fracture is $1.3 \%$ but when it comes to elderly it is much high of about $8 \%$ and among tibial fractures more than $50 \%$ are tibial plateau fracture. In younger individuals high energy fractures are more common whereas in older people low energy fracture is more common as it occurs secondary to osteopenia ${ }^{[2]}$. These injuries if not properly managed it would lead onto complications such as non-union, infection and post-traumatic arthritis. Each type of tibial plateau fracture has its own characteristic morphology and the mode of treatment differs ${ }^{[3]}$. It is highly recommended to determine the force of injury along with the assessment of soft tissue and neurovascular damage before planning the operational management.

There was a controversy for a long time in the treatment options for tibial plateau fractures, as it is managed both by operative and conservative management. 
Previous studies had shown satisfactory results in both open and closed treatment options depending upon on the type and tibial plateau fracture ${ }^{[4]}$. The various type of managing the tibial plateau fractures apart from conservative management are open reduction and internal fixation, closed reduction and percutaneous fixation and hybrid type of external fixation ${ }^{[5]}$. The ultimate objective in the management of tibial plateau fracture is to ensure anatomic reduction, restore the axial alignment and maintain a stable fixation such a way to prevent the secondary displacement of fracture fragment ${ }^{[6]}$.

The three factors namely, joint incongruity, axial malalignment and instability will act alone or together for causing posttraumatic osteoarthritis ${ }^{[7-9]}$. So the success of treatment for tibial plateau fracture lies in maintaining the joint stability, making the articular surfaces more congruous and finally painless joint with a good range of mobility. Though ORIF is considered as the best technique but at time it compromises the soft tissues and it would result in high rate of postoperative wound infection ${ }^{[10-12]}$.

Most of the previously done studies had only assessed the general outcome of these fractures after management and only very few studies had assessed the functional outcome which is more important in patient's perspective and so the present study was designed to evaluate the functional outcome of osteosynthesis of tibial plateau fractures using different surgical techniques after a minimum period of 6 months by using Rasmussen scoring system.

\section{Methodology}

A prospective longitudinal study was conducted for a period of one year in a tertiary care hospital in Salem. The study was started after getting approval from the institutional ethical committee and the informed consent was obtained from all the study subjects involved in our study. All patients with proximal tibial fracture in the age group between 20 and 60 years were included as our study subjects. Patients presented with neurovascular injuries were excluded from the study and a total of 38 patients satisfying our inclusion and exclusion criteria were taken as our study subjects. A semi-structured questionnaire was formed to collect the socio-demographic details and the details related to the nature of trauma. The tibial fractures were classified based on schatzker type of fracture classification. Anesthesia fitness was obtained for all patients involved in the study and the operative procedure was done either under general or spinal anesthesia. The operating limb was cleaned and drapped. Fracture reduction was done under C-arm guidance by closed methods using ligamentotaxis. Combined traction with Valgus or varus strain was done in flexion or extension of knee as per the need of the individual case. Compression bony clamp was used in cases to bring the fracture fragments together. After confirming the reduction under $\mathrm{C}$-arm guidance fixation of the fracture was done with locking plate. In cases of schatzker type III tibial plateau fracture, the fracture depression was elevated with bent Steinmann pin introduced from the opposite condyle with or without bone grafting. After proper wound wash, wound was closed in layers with drain insitu. Postoperatively standard anteroposterior and lateral radiographs were taken. Functional outcome assessment of knee joint was done after six months post-operatively by using Rasmuseen score, which includes pain perception, walking capacity, extension at knee joint, range of movements and stability. All data were entered and analysed using SPSS version 24. Mean and SD were calculated for all parametric variables and percentage was derived for frequency variables.
Chi-square test was used to derive the statistical inference.

\section{Results}

In our study majority of the study patients were in the age group between 30 and 50 years with a sex ratio of 1.3: 1(table 1). Based on the side of injury, majority $(60 \%)$ had left side tibial fracture and for $90 \%$ of the patients the mode of injury was through road traffic accident and for the remaining $10 \%$ it was an accidental fall. The type of tibial plateau fracture was classified as per Schatzker classification. In the present study it is shown that type II tibial plateau fracture $(42.1 \%)$ was the most common type followed by type VI fracture (21\%) and type V $(13.1 \%)$ and the incidence of type I, III and IV is $7.8 \%$ (table 2). In our study for patients with type I tibial plateau fractures closed reduction with cancellous screw fixation was performed for all the patients, among patients with type II fractures open reduction with internal fixation along with elevation plateau and buttress plating was done for majority of the subjects and for $38 \%$ of patients with type II fractures bone grafting was done along with this procedure and a similar type of procedure was performed for patients with type III, IV and V tibial plateau fractures. ORIF with dual plating was performed for majority of the patients with type VI fractures (table 3). Patients functional outcome was assessed using Rasmussen functional grading in which the grading ranges from excellent to poor. For majority of the patients who had undergone closed reduction with cancellous screw procedure or open reduction and internal fixation with buttress plate and bone graft had the functional outcome between excellent and good whereas patients who had underwent dual plating had a fair to poor outcome and this difference was found to be statistically significant $(p<.05)$ (table 4). In the present study we found pain, knee stiffness and infection as the complications occurred in the patients post-operatively and all these complications were reported in very minimal subjects. Among these complications knee stiffness and pain were most common among the patients for whom dual plating was done and for the patients who had buttress plating and bone grafting, knee stiffness along with wound infection was common among the patients and the association was found to be statistical significant $(p<.05)$. As a long term complication varus type of deformity was reported in only one patient for whom buttress plating was performed. The pre-op and post-op X-ray pictures of few our patients is shown in Fig $1-3$.

Table 1: Age and gender wise distribution of the study subjects

\begin{tabular}{|c|c|c|c|}
\hline Age group & Male & Female & Total \\
\hline$<30$ & $3(13.6 \%)$ & $2(12.5 \%)$ & $5(13.1 \%)$ \\
\hline $30-40$ & $8(36.3 \%)$ & $5(31.2 \%)$ & $13(34.2 \%)$ \\
\hline $41-50$ & $7(31.8 \%)$ & $4(25 \%)$ & $11(28.9 \%)$ \\
\hline $51-60$ & $3(13.6 \%)$ & $3(18.7 \%)$ & $6(15.7 \%)$ \\
\hline$>60$ & $1(4.5 \%)$ & $2(12.5 \%)$ & $3(7.8 \%)$ \\
\hline Total & $22(100 \%)$ & $16(100 \%)$ & $38(100 \%)$ \\
\hline
\end{tabular}

Table 2: Distribution of the study subjects based on type of tibial plateau fracture as per Schatzker classification

\begin{tabular}{|c|c|c|}
\hline Type of tibial plateau fracture & Frequency & Percentage \\
\hline Type I & 3 & $7.8 \%$ \\
\hline Type II & 16 & $42.1 \%$ \\
\hline Type III & 3 & $7.8 \%$ \\
\hline Type IV & 3 & $7.8 \%$ \\
\hline Type V & 5 & $13.1 \%$ \\
\hline Type VI & 8 & $21 \%$ \\
\hline Total & 38 & $100 \%$ \\
\hline
\end{tabular}


Table 3: Type of tibial plateau fracture and the mode of interventional procedure

\begin{tabular}{|c|c|c|c|c|c|}
\hline \multirow[b]{2}{*}{$\begin{array}{l}\text { Type of tibial } \\
\text { fracture }\end{array}$} & \multicolumn{4}{|c|}{ Operative procedure } & \multirow[b]{2}{*}{ Total } \\
\hline & $\begin{array}{c}\text { Closed reduction with percutaneous } \\
\text { cancellous screw fixation }\end{array}$ & $\begin{array}{l}\text { ORIF + EV + } \\
\text { Buttress plate }\end{array}$ & $\begin{array}{l}\text { ORIF + EV + BG } \\
+ \text { Buttress plate }\end{array}$ & $\begin{array}{c}\text { ORIF + } \\
\text { Dual plating }\end{array}$ & \\
\hline Type I & $3(100 \%)$ & 0 & 0 & 0 & $3(7.8 \%)$ \\
\hline Type II & 0 & $11(73.3 \%)$ & $5(38.4 \%)$ & 0 & $16(42.1 \%)$ \\
\hline Type III & 0 & 0 & $3(23 \%)$ & 0 & $3(7.8 \%)$ \\
\hline Type IV & 0 & $3(20 \%)$ & 0 & 0 & $3(7.8 \%)$ \\
\hline Type V & 0 & $1(6.6 \%)$ & $2(15.3 \%)$ & $2(28.5 \%)$ & $5(13.1 \%)$ \\
\hline Type VI & 0 & 0 & $3(23 \%)$ & $5(71.4 \%)$ & $8(21 \%)$ \\
\hline Total & $3(100 \%)$ & $15(100 \%)$ & $13(100 \%)$ & $7(100 \%)$ & $38(100 \%)$ \\
\hline
\end{tabular}

Table 4: Type of operative procedure and the functional outcome assessed by Rasmussen functional grading

\begin{tabular}{|c|c|c|c|c|c|}
\hline Operative procedure & \multicolumn{3}{|c|}{ Rasmussen grading } & \multirow{2}{*}{ Total } & \multirow{2}{*}{ P value } \\
\cline { 2 - 5 } & Excellent & Good & Fair & Poor & \\
\hline Closed reduction with percutaneous cancellous screw fixation & $3(100 \%)$ & 0 & 0 & 0 & $3(100 \%)$ \\
\hline ORIF + EV + Buttress plate & $11(73.3 \%)$ & $3(20 \%)$ & $1(6.6 \%)$ & 0 & $15(100 \%)$ \\
\hline ORIF + EV + BG + Buttress plate & $6(46.1 \%)$ & $5(38.4 \%)$ & $2(15.3 \%)$ & 0 & $13(100 \%)$ \\
\hline ORIF + Dual plating & 0 & $4(57.1 \%)$ & $2(28.5 \%)$ & $1(14.2 \%)$ & $7(100 \%)$ \\
\hline Total & $20(52.6 \%)$ & $12(31.5 \%)$ & $5(13.1 \%)$ & $1(2.6 \%)$ & $38(100 \%)$ \\
\hline
\end{tabular}

( ) - row $\%$

Table 5: Type of operative procedure and the complications occurred

\begin{tabular}{|c|c|c|c|c|c|c|}
\hline \multirow{2}{*}{ Operative procedure } & \multicolumn{7}{|c|}{ Complications } & \multirow{2}{*}{$\begin{array}{c}\text { P } \\
\text { value }\end{array}$} \\
\cline { 2 - 7 } & Pain & $\begin{array}{c}\text { Knee } \\
\text { stiffness }\end{array}$ & Infection & $\begin{array}{c}\text { Varus } \\
\text { deformity }\end{array}$ & Nil & \\
\hline $\begin{array}{c}\text { Closed reduction with percutaneous } \\
\text { cancellous screw fixation }\end{array}$ & 0 & 0 & 0 & 0 & $3(100 \%)$ & $3(100 \%)$ \\
\hline ORIF + EV + Buttress plate & $2(13.3 \%)$ & 0 & 0 & $1(6.6 \%)$ & $12(80 \%)$ & $15(100 \%)$ \\
\hline ORIF + EV + BG + Buttress plate & $2(15.3 \%)$ & 0 & $2(15.3 \%)$ & 0 & $9(69.2 \%)$ & $13(100 \%)$ \\
\hline ORIF + Dual plating & $2(28.5 \%)$ & $3(42.8 \%)$ & 0 & 0 & $2(28.5 \%)$ & $7(100 \%)$ \\
\hline Total & $6(15.7 \%)$ & $3(7.8 \%)$ & $2(5.2 \%)$ & $1(2.6 \%)$ & $26(68.4 \%)$ & $38(100 \%)$ \\
\hline
\end{tabular}
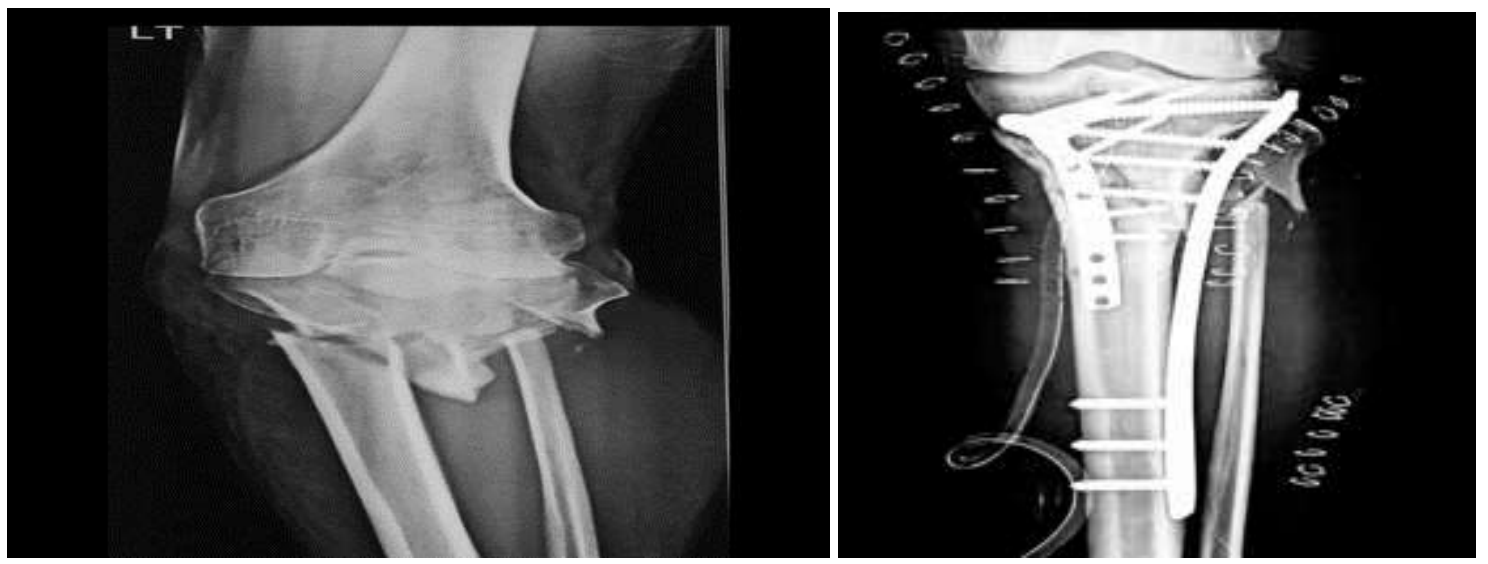

Fig 1: Pre-op X-ray and Post-op X-ray
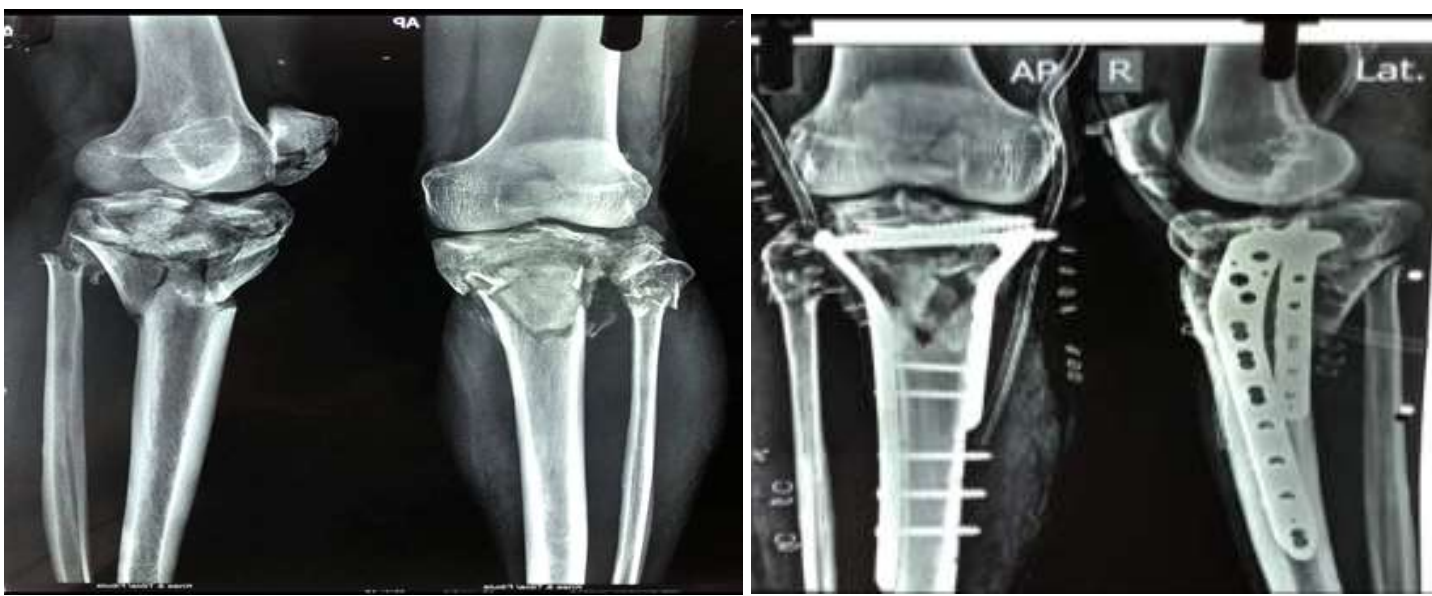

Fig 2: Case No 2 Pre-op and Post-op X-ray 

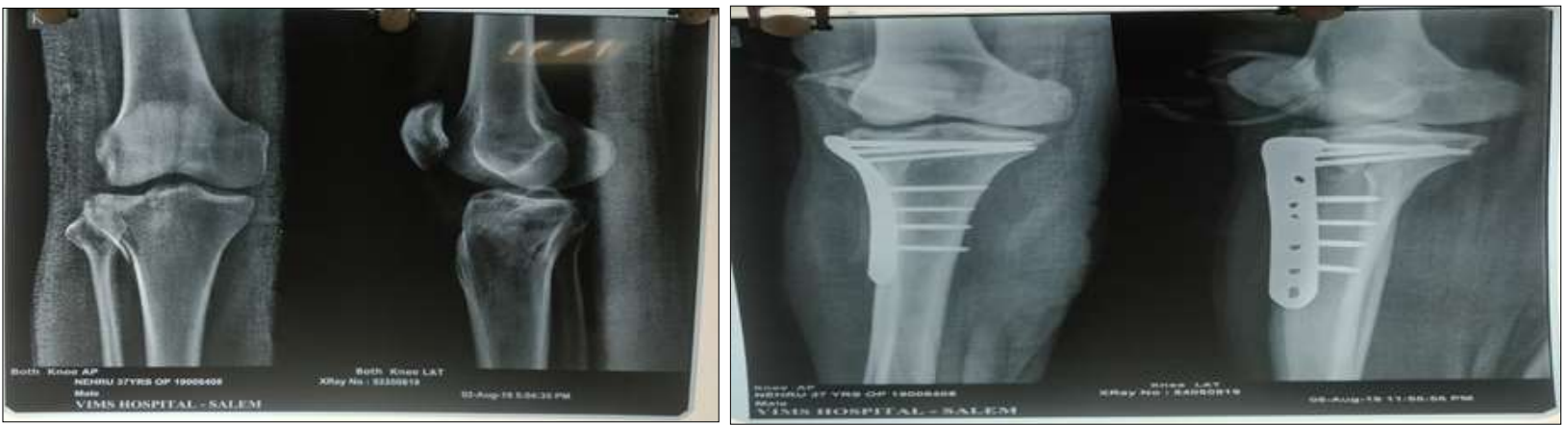

Fig 3: Case No 3 Pre-op and Post-op X - ray

\section{Discussion}

Fractures around the knee joint is of paramount important as these fractures if not properly treated would result in severe morbidity that would invariably affect the quality of life. Tibial condyle fracture resulting from high energy mechanism and those fractures that separates the tibial metaphysis from diaphysis are usually associated with comminuted fractures with extended soft tissue injury resulting in severe complications ${ }^{[13]}$. Conservative treatment for these types of fractures did not show a satisfactory outcome as quoted in few of the studies done on management techniques for tibial condyle fractures. Open reduction with internal fixation without damaging the soft tissues is the treatment of choice, which would lead to a fair to good results in $50 \%$ of these fractures ${ }^{[14]}$. Though ORIF is being followed by majority of surgeons for tibial plateau fractures the major disadvantage is higher risk of soft tissue injury during the procedure, knee stiffness and chances for acquiring wound infections is more. Minimal invasive plate osteosynthesis is a newer technique being followed for proximal and distal tibial fractures as it produces less handling of soft tissues that invariably leads to lesser chance of wound infections and resulting in a commendable outcome ${ }^{[15]}$. Knowing the merits and demerits of the various surgical procedures for managing tibial plateau fractures the current study was conducted with an objective to evaluate the functional outcome of osteosynthesis for proximal tibia fractures based on different treatment modalities. In our study the mean age of the patients reported with tibial plateau fracture was 39.2 years and it is almost similar to the previous studies done on tibial fractures in which majority of the studies had quoted $30-40$ years is the commonest age group affected with this type of fracture and a study done by Seppo etal almost correlates with our study mentioning the men age as 39.8 years ${ }^{[16]}$. Similarly as reported by the previous studies male predominance was more in the present study and road traffic accidents being the most common mode of injury. In our study according to Schatzker classification majority of the patients were reported with type II tibial plateau fracture followed by type VI fractures and a similar type of scenario was also seen in a study done at Finland and Toronto ${ }^{[17,18]}$. As quoted in the previous literature the most common modality of treating tibial plateau fracture is open reduction and internal fixation and the same was followed in our study also and the most common minimal invasive procedure done for tibial plateau fracture is percutaneous plate osteosynthesis and in our study we followed this procedure for type I tibial plateau fractures. In the present study $84 \%$ of the patients had good to excellent functional outcome and these results were attributed to patients who underwent early surgery and early mobilization. Only two patients developed post-operative wound infection and were treated aggressively with broad spectrum antibiotics and the infection resolved in one week. Similarly in a study done by Krettek etal, one case had wound infection for which wound debridement and re-suturing was done leaving the implant in-situ ${ }^{[19]}$. Three cases in the our study reported with post-operative knee stiffness which might be due to longer duration between injury and surgery and prolonged immobilisation, whereas the study done by Krettek etal did not had a single patient with knee stiffness for which he mentioned shorter interval between injury and surgery as the reason ${ }^{[19]}$

In the present study no incidence of delayed or non-union was reported which might be due to the preservation of the blood supply during the operative procedure and the same mechanism was highlighted by Borrelli and Krettek et al. ${ }^{[19,}$ ${ }^{20]}$ Hasnain Raza et al. in his study on functional outcome of tibial condyle fractures using Rasmussen functional scoring system found that majority of the patients had good to excellent functional outcome and only $10 \%$ had poor outcome with a mean rasmuseen score of $25.8^{[21]}$. Similarly in our study the mean rasmuseen score was found to be 25.5 with $84 \%$ of patients showing good to excellent outcome.

Chang-Wug Oh et al. in their study on double plating for type $\mathrm{V}$ and type VI proximal tibial fractures using minimally invasive percutaneous osteosynthesis procedure have found more than $80 \%$ with excellent scoring and functional outcome with a mean rasmuseen score of 26 and the results are almost in par with our study with respect to type $\mathrm{V}$ and type VI proximal tibial fracture management ${ }^{[22]}$. Sample size being the only limitation of the present study, choosing the surgical procedure based on type of fracture, quality of bone and intraoperative reduction produces least complications with good knee mobility.

\section{Conclusion}

In the management of tibial plateau fractures, open reduction with internal fixation using plate screws with lesser soft tissue dissection would lead to excellent functional outcome. Lesser the duration between injury and surgery, lesser the duration of immobilisation and reduced incidence of post-operative infection are the other factors that influence the functional outcome in tibial plateau fractures.

\section{References}

1. Koval KJ, Helfet DL. Tibial plateau fractures: evaluation and treatment. J Am Acad Orthop Surg 1995;3(2):86-94.

2. Joon-Woo Kim, Chang-Wug Oh, Won-Ju Jung, and JiSoo Kim, Minimally Invasive Plate Osteosynthesis for Open Fractures of the Proximal Tibia. Clin Orthop Surg. 2012;4(4):313-320.

3. Monappa A Naik, Gaurav Arora, Sujit Kumar Tripathy, Sarath K Rao. Clinical and radiological outcome of percutaneous plating in extra-articular proximal tibia 
fractures: A prospective study. Injury 2013;44(8):10811086.

4. Cole P, Levy B, Schatzker J, Watson JT. Tibial plateau fractures. In: Browner B, Levine A, Jupiter J, Trafton P, Krettek C, eds. Skeletal Trauma: Basic Science Management and Reconstruction. Philadelphia, PA: Saunders Elsevier, 2009, 2201-2287.

5. Papagelopoulos PJ, Partsinevelos AA, Themistocleous GS, Mavrogenis AF, Korres DS, Soucacos PN. Complications after tibia plateau fracture surgery. Injury. 2006;37:475-84

6. Watson JJ, Wiss AD. Fractures of the proximal tibia and fibula, chapter 44 in Rockwood and.

7. Moore TM, Patzakis MJ, Harvey JP. Tibial plateau fractures: definition, demographics, treatment rationale and long term results of closed traction management or operative reduction. J Orthop Trauma 1987;2:97-117.

8. William S, Mills J, Sean Nork E. Open reduction and internal fixation of high energy tibial plateau fractures. Orthop clinic. North America 2002;33:177-98.

9. Young MJ, Barrack RL. Complications of internal fixation of tibial plateau fractures. Orthop Rev 1994;23:149-54

10. Lee JA, Papadakis SA, Moon C, Zalavras CG. Tibial plateau fractures treated with the less invasive stabilisation system. Int Orthop 2007;31:415-418.

11. Feng W, Fu L, Liu J, Qi X, Li D, Yang C. Biomechanical evaluation of various fixation methods for proximal extra-articular tibial fractures. J Surg Res 2012;178:722727.

12. Kim JW, Oh CW, Jung WJ, Kim JS. Minimally invasive plate osteosynthesis for open fractures of the proximal tibia. Clin Orthop Surg 2012;4:313-320.

13. Hassankhani EG, Kashani FO, Hassankhani GG. Treatment of complex proximal ${ }^{[14]}$ tibial fractures (types $\mathrm{v} \&$ vi of schautzker classification) by double plate fixation with single anterior incision. Open journal of Ortho 2013;3:208-12.

14. Barei DP, Nork SE, Mills WJ, Henley MB, Benirschke SK. Complications ${ }^{[15]}$ associated with internal fixation of high-energy bicondylar tibial plateau fractures utilizing a two-incision technique. J Orthop Trauma. 2004;18(10):649-57.

15. Barei DP, Nork SE, Mills WJ, Coles CP, Henley MB, Benirschke SK. Functional [16] out-comes of severe bicondylar tibial plateau fractures treated with dual incision and medial and lateral plates. J Bone Joint Surg Am 2006;88(8):1713-21.

16. Honkonen SE. Indications for surgical treatment of tibial condyle fractures. Clin Orthop 1994;302:199-205.

17. Stenroos A, Pakarinen H, Jalkanen J, Mälkiä T, Handolin L. Tibial Fractures in Alpine Skiing and Snowboarding in Finland: A Retrospective Study on Fracture Types and Injury Mechanisms in 363 Patients. Scandinavian Journal of Surgery 2016;105(3):191-196.

18. Schatzkar J, Mc Broom R, Bruce D. The tibial plateau fractures-Toronto experience. Clin Orthop 1979;138:94.

19. Krettek C, Gosling T, Schandelmaier P, Muller M, Hankemeier S, Wagner M. Single lateral locked screw plating of bicondylar tibial plateau fractures. Clin Orthop Relat Res 2005;439:207-14.

20. Borrelli J, Koval KJ, Sanders R, Helfet D, DiPasquale T, Mast JW. Indirect reduction and percutaneous screw fixation of displaced tibial plateau fractures. J Orthop Trauma 1992;6(3):340-6.
21. Hasnain Raza. Minimally invasive plate osteosynthesis for tibial plateau fractures, Journal of orthopaedic surgery 2012;20(1):42-7.

22. Jong-keun O, Chang-wug O, In-Ho J, Sung-Jung K, HeeSoo K, Il-Hyung P, et al. Percutaneous plate stabilisation of prximaltibial fractures. J Truama 2005;5:431-7. 